\title{
Development of Novel Multiplex PCR for Diagnosis of Co-infected Hemo-parasites in Cattle
}

Pankaj Kumar, Abhay Kumar, Kamal Sarma,

Paresh Sharma1, Rashmi Rekha Kumari², Manish Kumar ${ }^{3}$

10.18805/IJAR.B-4695

\begin{abstract}
Background: A novel, rapid and specific multiplex polymerase chain reaction was developed to diagnose hemo-parasitic infection in bovine blood co-infected with three of the most common hemo-parasites.

Methods: The diagnostic process relied on the detection of the three different bovine hemoparasites isolated from red blood cells (RBCs) of cattle $(\mathrm{N}=30)$ by conventional Giemsa stained blood smear (GSBS) and confirmed by multiplex PCR. The multiplex PCR system was used to diagnose GSBS positive blood samples $(\mathrm{N}=12)$ found infected or co-infected with hemoparasites. The designed multiplex primer sets was attempted to amplify 205, 313 and 422 bp fragments of apocytochrome $b$, sporozoite and macroschizont 2 (spm2) and 16S rRNA gene for Babesia bigemina, Theileria annulata and Anaplasma marginale, respectively.

Result: This multiplex PCR was sensitive with the ability to detect the presence of $150 \mathrm{ng}$ of genomic DNA. The primers used in this multiplex PCR also showed highly specific amplification of specific gene fragments of each respective parasite. Comparing the two detection methods revealed that $58.33 \%$ of specimens showed concordant diagnoses with both techniques. The specificity, positive predictive value and kappa coefficient of the agreement was highest for diagnosis of $B$. bigemina and lowest for $A$. marginale. The overall Kappa coefficient for diagnosis based on GSBS for multiple pathogens compared to multiplex PCR was 0.56 , slightly behind the threshold of 0.6 of agreement. Therefore, confirmation should always be based on PCR to rule out false positives due to differences in subjective observations, stain particles and false negatives due to low parasitemia. The simplicity and rapidity of this specific multiplex PCR method make it suitable for large-scale epidemiological studies and follow-up of drug treatments.

Key words: Anaplasma, Babesia, Co-infection, Multiplex PCR, Theileria.
\end{abstract}

\section{INTRODUCTION}

Recent studies suggest that vector-borne diseases have emerged due to climate change in tropical countries (Balakrishnan, 2017; El-Sayed and Kamel, 2020; Kumar et al. 2021; Kumari et al. 2019). The tick population has increased considerably, leading to higher tick-borne infections in a susceptible host. It was observed that the cattle population often suffer from co-infection of more than one pathogen transmitted by the ticks. These infections cannot be diagnosed symptomatically as the symptoms are overlapping and elusive. Similarly, microscopic examination based on conventional blood smear examination often requires expertise observation and may sometimes be misleading in co-infections or due to subjective observations. PCR based diagnosis is very specific and sensitive in detecting these pathogens. However, it may require multiple PCR for diagnosis of pathogen load in samples suspected to have co-infections. Considering these limitations of diagnosis of co-infected tick-transmitted pathogens, an attempt has been made to design a multiplex PCR to detect co-infections of these pathogens in a single run with the objective to provide a prompt and complete diagnosis to the farmers.

\section{MATERIALS AND METHODS Ethics}

The study involved drawing $3 \mathrm{ml}$ blood from the jugular vein aseptically from clinically affected animal with the owners'
ICAR-Research Complex for Eastern Region, Patna P.O. Bihar Veterinary College, Patna-800 014, Bihar, India.

${ }^{1}$ National Institute of Animal Biotechnology, Hyderabad-500 032, Telangana, India.

2Department of Veterinary Pharmacology and Toxicology, Bihar Veterinary College, Bihar Animal Sciences University, Patna-800 014, Bihar, India.

${ }^{3}$ Department of Biosciences and Bioengineering, Indian Institute of Technology Guwahati, Guwahati-781 039, Assam, India.

Corresponding Author: Pankaj Kumar, Division of Livestock and Fisheries Management, ICAR Research Complex for Eastern Region, Patna-800 014, Bihar, India.

Email: pankaj.kumar1@icar.gov.in

How to cite this article: Kumar, P., Kumar, A., Sarma, K., Sharma, P., Kumari, R.R., Kumar, M. (2021). Development of Novel Multiplex PCR for Diagnosis of Co-infected Hemo-parasites in Cattle. Indian Journal of Animal Research. 55(12): 1504-1509. DOI: 10.18805/IJAR.B-4695.

Submitted: 26-06-2021 Accepted: 31-08-2021 Online: 09-09-2021

consent. These were either brought for treatment to veterinary hospitals or a local veterinarian's call for treatment at the farmer's door. There are no ethical guidelines for the blood sample collection from clinical cases, so no prior approval was mandatory. Treatment was provided to all animals sampled. 


\section{Animal}

Blood samples were selectively collected from crossbred cattle (Bos taurus $\times$ Bos indicus breeds) $(n=30)$ in an EDTA vacutainer tube and a clot activator tube (BD, Franklin, USA) suspected to have an infection of tick-transmitted diseases. Cattle were chosen from the farmer's field, dairy farms and veterinary hospitals around endemic pockets of Manner block of the peri-urban Patna located in the Gangetic plains of Bihar, India. The selection of cattle was made on the available clinical history and symptoms associated with tick infestation. The study was carried out in 2019-21 at ICAR Research Complex for Eastern Region, Patna.

\section{Clinical examination}

Selected animals from the endemic area were clinically examined during sampling. Rectal temperature, mucosal membranes, pre-scapular lymph nodes and respiration pattern were also observed. The eyes were examined for any opacity or abnormal discharge.

\section{Blood examination}

The collected blood samples were processed for microscopic examination, hematological examination and whole blood genomic DNA isolation. A duplicate thin smear was prepared on a glass slide from each sample and fixed with methanol for 5 min for microscopic examination of blood and lymphnode aspirate. The fixed smear on the glass slide was stained with Giemsa stain (Himedia) for 20 min, washed, air-dried and examined under oil (100x) immersion. The presence of piroplasms in blood smear through microscopic examination was considered positive for Theileria spp. The hemoglobin $(\mathrm{Hb})$ concentration $(\mathrm{g} / \mathrm{dL})$ in blood was measured using HemoCue ${ }^{\circledR}$ cuvettes and its analyzer. PCV was calculated based on correlation between hemoglobin and PCV expressed as $\mathrm{Hb}$ concentration $(\mathrm{g} / \mathrm{dL})=0.3 \mathrm{PCV}+3$ (Turkson and Ganyo 2015). RBC count and WBC counts were measured manually under the microscope by routine procedures (Jain, 1999).

\section{DNA isolation}

Infected blood samples (300 $\mu \mathrm{L})$ found positive based on GSBS was used to extract whole genomic DNA using a commercial kit (GCC) as per the manufacturer's instruction and stored at $-20^{\circ} \mathrm{C}$. The quality and quantity of genomic DNA were checked by running the extracted DNA on agarose gel $(1 \%)$ and the purity was measured using nanodrop readings.

\section{Primer designing}

The primer was designed to identify the three most common pathogens (Theileria annulata, Anaplasma marginale and Babesia bigemina) in bovine based on our experience and infection prevailing in the region (Table 1). All three pathogens' primers were designed to get nearly similar melting temperatures $\left(\mathrm{Tm} \sim 57-59^{\circ} \mathrm{C}\right)$. Primer for $T$. annulata (313 bp) was designed using NCBI reference sequence XM_947453.1 for 2763 bp sequence of T. annulata Spm2 protein partial mRNA (Pain et al. 2005). The sporozoite and macroschizont 2 (spm2) gene sequence is specific to $T$. annulata parasitic infection (Prabhakaran et al. 2021; Tian et al. 2018). Primer for simultaneous detection of $A$. marginale (422 bp) was designed using NCBI reference sequence for $16 \mathrm{~S}$ ribosomal RNA sequence of $A$. marginale str. Florida as Gene ID-7398331. The primer for the third common pathogen, B. bigemina (205 bp), was designed using NCBI reference nucleotide sequence $A F 109354.1$ for 720 bp of apocytochrome $b$ gene (Bilgiç et al. 2013).

\section{Multiplex PCR}

The thermal PCR program was standardized for multiplex PCR to detect the genomic DNA of three hemo-parasite ( $T$. annulata, B. bigemina and $A$. marginale) in a single run using DNA extracted from cattle blood samples. All isolated DNA samples from cattle blood found infected with single or multiple hemo-parasite by GSBS were used to run the multiplex PCR.

Table 1: List of primers designed from target genes for simultaneous diagnosis of $T$. annulata, A. marginale and B. bigemina by multiplex PCR.

\begin{tabular}{lclcc}
\hline Pathogens & Target gene & Sequence $\left(5^{\prime}-3^{\prime}\right)$ & Tm $\left({ }^{\circ} \mathrm{C}\right)$ & Amplicon size \\
\hline T. annulata & spm2 & ATGAGACAAAAGAAAGTAAAGACCA & 57.7 & $313 \mathrm{bp}$ \\
& & GAAGTTCCCTGGTTATTTTGGTC & 60.1 & $205 \mathrm{bp}$ \\
B. bigemina & apocytochrome $b$ & TTGGGCACTTCGTTATTTCC & 59.9 & 59.3 \\
& & TGTTGCTCCCCAGTAACTCA & 59.3 & $422 \mathrm{bp}$ \\
A. marginale & \multirow{2}{*}{ 16S rRNA } & GGGGTAATGGCCTACCAAG & 59.3 \\
\hline
\end{tabular}

Table 2: Hematology of crossbred cattle diagnosed for tick transmitted pathogens based on GSBS.

\begin{tabular}{|c|c|c|c|c|}
\hline GSBS findings & Hemoglobin (mg/L) & RBC count $\left(\times 10^{6} / \mu L\right)$ & WBC count $\left(\times 10^{3} / \mu \mathrm{L}\right)$ & $\mathrm{PCV}(\%)$ \\
\hline T. annulata $(\mathrm{n}=7)$ & $7.39^{a} \pm 0.43(3.50-5.70)$ & $4.20^{\mathrm{a}} \pm 0.20(1.64-3.24)$ & $6.45^{\mathrm{a}} \pm 0.45(5.12-8.21)$ & $14.71^{\mathrm{a}} \pm 1.46(9.0-21.0)$ \\
\hline A. marginale $(\mathrm{n}=9)$ & $7.69^{a} \pm 0.44(5.8-9.6)$ & $5.54^{\mathrm{b}} \pm 0.28(3.98-6.42)$ & $5.99^{a} \pm 0.31(4.89-7.12)$ & $15.67^{\mathrm{a}} \pm 1.50(9.0-22.0)$ \\
\hline Co-infections $(n=7)$ & $6.74^{\mathrm{a}} \pm 0.37(5.8-8.3)$ & $4.54^{\mathrm{a}} \pm 0.23(3.88-5.62)$ & $5.57^{\mathrm{a}} \pm 0.31(4.66-6.84)$ & $12.43^{\mathrm{a}} \pm 1.29(9.00-18.0)$ \\
\hline Negative $(n=7)$ & $10.94^{\mathrm{b}} \pm 0.23(9.9-11.8)$ & $7.78^{c} \pm 0.34(6.24-8.92)$ & $7.85^{\mathrm{b}} \pm 0.41(6.38-9.45)$ & $26.29^{b} \pm 0.75(23.0-29.0)$ \\
\hline Reference range (Jain, 1999) & $8.0-15.0$ & $5-10$ & $4-12$ & $24-46$ \\
\hline
\end{tabular}

Values in column with different superscript varies significantly $(P<0.05)$. 
Briefly, PCR assay was performed in a total volume of $25 \mu \mathrm{l}$ containing $3 \mu \mathrm{l}(50 \mathrm{ng} / \mu \mathrm{l})$ of the genomic DNA and $2 \mu \mathrm{l}$ primers each of forward and reverse primer prepared after mixing of equal volume of 10 micro-molar working solution of the three forward and reverse primers and $12.5 \mu \mathrm{l}$ of OneTaq Hot Start master mix with buffer (Imperial Life Sciences (P) Limited) and ultra-pure nuclease free water to make the final volume. Amplification involved a hot start of $5 \mathrm{~min}$ at $95^{\circ} \mathrm{C}$, followed by 35 cycles of $1 \mathrm{~min}$ at $95^{\circ} \mathrm{C}, 1 \mathrm{~min}$ at $58^{\circ} \mathrm{C}$, $1 \mathrm{~min}$ at $72^{\circ} \mathrm{C}$ and a final extension step of $10 \mathrm{~min}$ at $72^{\circ} \mathrm{C}$.

The amplified PCR products were subjected to electrophoresis on $2 \%$ agarose gel stained with ethidium bromide, visualized under UV light and photographed in trans-illuminator apparatus. The amplicons molecular sizes were estimated by including a Quick-Load 100 bp DNA Ladder (Imperial Life Sciences Private Limited) and visualized and documented on Gel-Doc (Azure Biosystems c200). DNA positive controls of $T$. annulata were kindly provided by NIAB, Hyderabad. The positive control of $A$. marginale (MK834271) and B. bigemina (MH936010) was used from DNA found positive after specific amplification and sequencing for species-specific amplified products. Distilled water served as a negative control.

\section{Statistics}

Data were analyzed for mean and standard error. Analysis of variance (ANOVA) using post hoc LSD test of

Table 3: Comparison of observation based on conventional GSBS examination and multiplex PCR developed.

\begin{tabular}{lcccccc}
\hline \multirow{2}{*}{ Sample no. } & \multicolumn{3}{c}{ GSBS } & \multicolumn{4}{c}{ Multiplex PCR } \\
\cline { 2 - 7 } & A & T & B & A & T & B \\
\hline 1 & $+v e$ & $-v e$ & $-v e$ & $+v e$ & $+v e$ & $-v e$ \\
2 & $+v e$ & $+v e$ & $-v e$ & $+v e$ & $+v e$ & $-v e$ \\
3 & $+v e$ & $+v e$ & $-v e$ & $+v e$ & $+v e$ & $-v e$ \\
4 & $+v e$ & $+v e$ & $-v e$ & $+v e$ & $+v e$ & $-v e$ \\
5 & $-v e$ & $+v e$ & $-v e$ & $+v e$ & $+v e$ & $-v e$ \\
6 & $+v e$ & $-v e$ & $-v e$ & $-v e$ & $-v e$ & $+v e$ \\
7 & $-v e$ & $+v e$ & $+v e$ & $-v e$ & $+v e$ & $+v e$ \\
8 & $-v e$ & $+v e$ & $+v e$ & $-v e$ & $+v e$ & $+v e$ \\
9 & $+v e$ & $-v e$ & $+v e$ & $-v e$ & $-v e$ & $+v e$ \\
10 & $-v e$ & $+v e$ & $-v e$ & $-v e$ & $-v e$ & $+v e$ \\
11 & $+v e$ & $+v e$ & $-v e$ & $-v e$ & $+v e$ & $-v e$ \\
12 & $+v e$ & $-v e$ & $-v e$ & $+v e$ & $-v e$ & $-v e$ \\
\hline
\end{tabular}

Where, $\mathrm{A}=A$. marginale; $\mathrm{B}=\mathrm{B}$. bigemina; $\mathrm{T}=T$. annulata; +ve: Positive; -ve: Negative. significance, if any, was observed at $P<0.05$. The observation of GSBS and multiplex PCR was compared for sensitivity $\left(S_{e}\right)$, specificity $\left(S_{p}\right)$, positive predictive values (PPV) and negative predictive value (NPV) by the method elaborated earlier (Trevethan, 2017). Cohen's kappa coefficient was calculated by the method described (Landis and Koch, 1977).

\section{RESULTS AND DISCUSSION}

Tick transmitted diseases with high infection in the bovine population of Bihar with Theileria spp., A marginale and $B$. bigemina and their co-infection has been frequently reported (Kala et al. 2018; Kumar et al. 2019; Kumar et al. 2021; Prabhakaran et al. 2021; Roy et al. 2021). The study indicated that the endemic region had high $(76.67 \%)$ infection of tick-transmitted hemo-parasite in selected crossbred cattle based on conventional Giemsa blood smear examination (Fig 1). Our findings also suggest a high infection rate of these hemo-parasite and association of more than one type of parasite in the animals screened by GSBS. These results have few limitations and are dependent on expert examination and staining procedures (Prabhakaran et al. 2021). The infected animals had clinical signs such as high fever, drop in milk yield, inappetence to anorexia. $30.44 \%$ of infected cattle were co-infected with more than one hemo-parasite. The hematological changes observed in these cattle are indicative of significant RBCs destruction, anemia (reduced $\mathrm{Hb}$ level) and leukopenia in infected cattle compared to non-infected cattle (Table 2). These changes are associated with the capability of infecting parasites to reach the circulation and invade the RBCs and corroborates with earlier findings from mixed infected cattle of southern India (Jayalakshmi et al. 2019). The severity of changes varied depending upon the type and degree of RBCs infected by these parasites. The study corroborated earlier reports associated with tick-transmitted hemoparasite in cattle (Ganguly et al. 2017; Larcombe et al. 2019; Prabhakaran et al. 2021) and buffaloes (Kumar et al. 2021). Molecular confirmation based on PCR amplification requires multiple attempts to detect co-infected samples. Therefore, the confirmatory molecular diagnostic method was developed to detect a co-infected state in the animal in a single run by multiplex PCR using specific gene primers, which was found useful and corroborates with the findings of GSBS. Spm2 gene used for detecting T. annulata has not been attempted earlier for multiplex PCR development.

Table 4: Comparison of sensitivity $\left(\mathrm{S}_{\mathrm{e}}\right)$, specificity $\left(\mathrm{S}_{\mathrm{p}}\right)$, positive predictive values (PPV), negative predictive values (NPV) and Cohen's kappa coefficient of the GSBS observation with multiplex PCR.

\begin{tabular}{lccccc}
\hline Pathogens & $\mathrm{S}_{\mathrm{e}}(\%)$ & $\mathrm{S}_{\mathrm{p}}(\%)$ & PPV (\%) & NPV (\%) & Kappa coefficient \\
\hline $\mathrm{A}$ & 83 & 50 & 62.5 & 75 & 0.34 \\
$\mathrm{~T}$ & 87.5 & 75 & 87.5 & 75 & 0.62 \\
$\mathrm{~B}$ & 60 & 100 & 100 & 22.2 & 0.63 \\
$\mathrm{~A}+\mathrm{T}+\mathrm{B}$ & 78.9 & 76.5 & 78.9 & 76.5 & 0.56 \\
\hline
\end{tabular}

Where, $\mathrm{A}=A$. marginale; $\mathrm{B}=B$. bigemina; $\mathrm{T}=T$. annulata; Kappa coefficient of 0.6 and above is considered as in agreement. 
It has been reported to be expressed both in sporozoites and in later stages (macroschizont-infected leucocytes and piroplasms) of the life-cycle of $T$. annulata (Knight et al. 1998). Apocytochrome $b$ gene has been reported to be very effective for detecting $B$. bigemina and $B$. bovis by targeting a species-specific region of this gene (Ganzinelli et al. 2020). Similar methods of multiplex PCR are also reported based on different target genes. Kundave et al. (2018) developed multiplex PCR using Tams1, 18S rRNA and 16S rRNA genes of $T$. annulata, $B$. bigemina and $A$. marginale, respectively. Bilgiç et al. (2013) developed a multiplex PCR assay for simultaneous detection of $T$. annulata, $A$. marginale and $B$. bovis in cattle using cytochrome $b$ gene, major surface protein-1 $\beta$ encoding gene and VESA- $1 \alpha$ gene, respectively. Multiplex PCR based on species-specific primers was observed to be useful and $100 \%$ specific in detecting the co-infection of tick-transmitted hemo-parasite in a single run (Table 3). The visualization was clear and specific on gel doc examination (Fig 2). Negative samples did not result in any amplification. Further, the results of multiplex PCR considered as confirmatory were compared with results of GSBS. The unmatched results of GSBS were considered as false positive and negative. The sensitivity $\left(S_{e}\right)$, specificity $\left(S_{p}\right)$, positive predictive values (PPV), negative predictive values (NPV) and Cohen's kappa coefficient of the GSBS observation with multiplex PCR are depicted in Table 4. The $S_{p}$, PPV and kappa coefficient of the agreement was highest for diagnosis of $B$. bigemina and lowest for $A$. marginale. The $S_{e}$ was highest for detection of $T$. annulata and lowest for $B$. bigemina. The results of $S_{e}, S_{p}, P P V, N P V$ and Cohen's

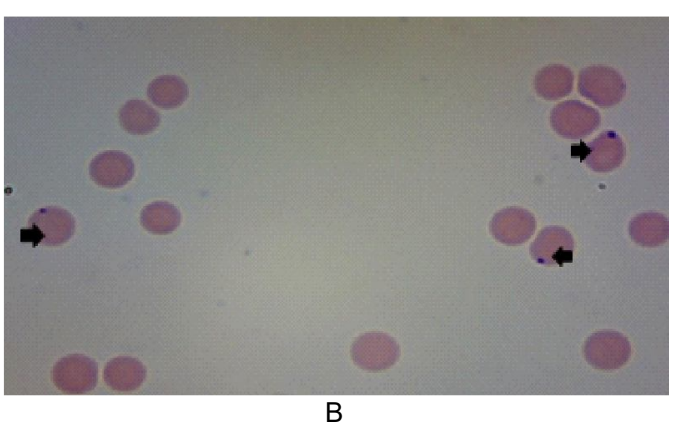

A
$+$

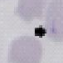

$+$
B

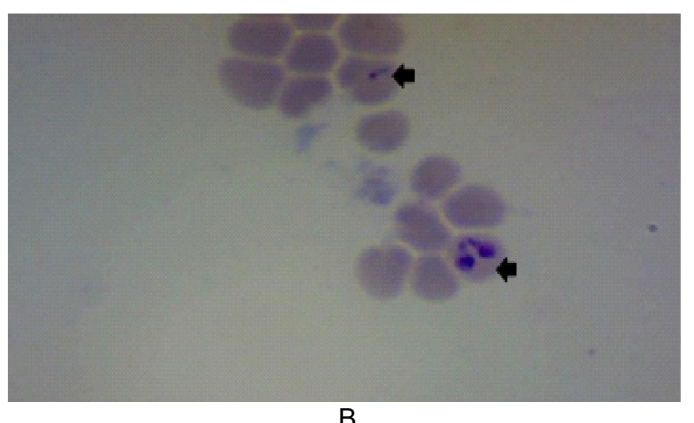

B

Fig 1: Diagnosis based on conventional GSBS. Representative photographs were taken under oil immersion microscope 1000x magnification. A. Infected RBCs (arrow) with T. annulata prioplasm; B. Infected RBCs with A. marginale (arrow); C. Infected RBCs with $B$. bigemina (paired pear-shaped bodies) and $T$. annulata (above arrow)

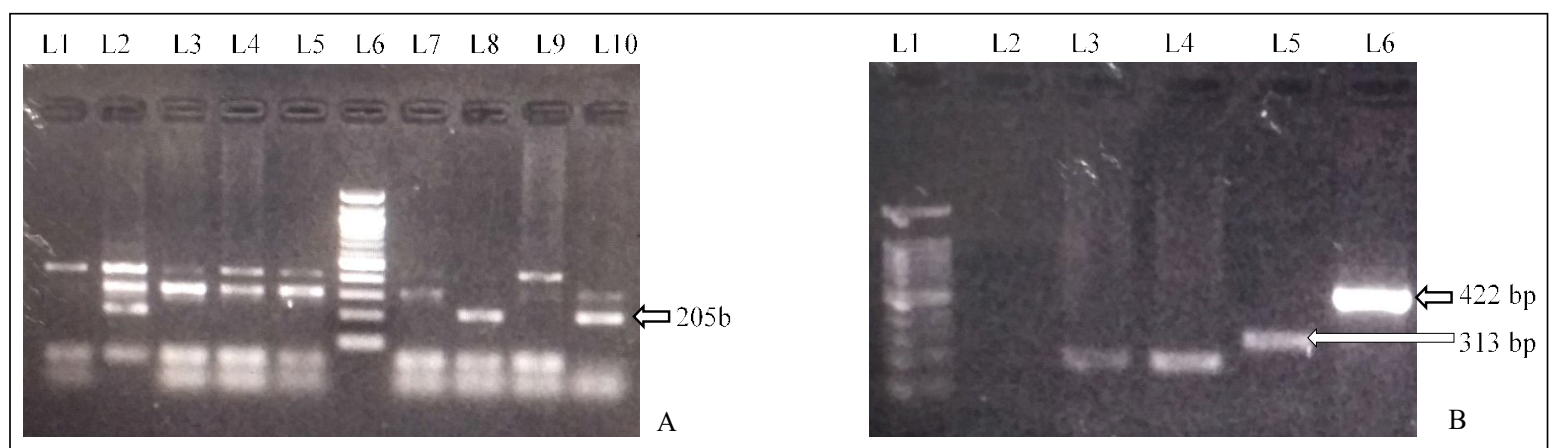

Fig 2: Multiplex PCR product agarose gel electrophoresis visualized under UV light of Gel Doc with positive amplification at 205, 313 and 422 bp for B. bigemina, T. annulata and A. marginale, respectively. A. Lane 1: Positive control; Lane 6: 100 bp Ladder; Remaining lanes (L2, I3, L4, L5, L7, L8, L9, L10): Samples 1-8); B. Lane 1:100 bp ladder; Lane 2: Negative control; Remaining lanes (L3, L4, L5, L6): Samples 9-12. 
kappa coefficient of the GSBS observation with multiplex $\mathrm{PCR}$ indicates that diagnosis of $A$. marginale is difficult with GSBS attributed to the similarity of $A$. marginale with staining artefacts and sometimes polymorphic attributes of $T$. annulata. On the contrary, the diagnosis of $B$. bigemina had high $S_{p}$, PPV, which is attributed to the sampling of animals mostly after characteristic clinical symptoms of red urine. The overall Kappa coefficient for diagnosis of these parasites by both the test are in moderate $(0.56)$ agreement, though has high $\mathrm{S}_{\mathrm{e}}(78.9), \mathrm{S}_{\mathrm{p}}$ (76.5) and PPV (78.9) percentage. Landis and Koch (1977) have proposed the following as standards for strength of agreement for the kappa coefficient: $\leq 0=$ poor, $0.01-0.20=$ slight, $0.21-0.40=$ fair, $0.41-0.60=$ moderate, $0.61-0.80=$ substantial and $0.81-$ $1=$ almost perfect. Cohen's kappa coefficients indicate that the diagnosis of $T$. annulata and B. bigemina is in substantial agreement with the GSBS observation with obvious reason of sampling from animals with characteristic though overlapping clinical symptoms. This multiplex PCR can detect false negative samples based on GSBS due to low level of parasitemia and rectify false-positive results due to differences in subjective observations.

\section{CONCLUSION}

A new method of multiplex PCR has been developed for simultaneous detection of $T$. annulata, $B$. bigemina and A. marginale in cattle in a single run. This method will be helpful for researchers to diagnose co-infection of tick transmitted diseases in cattle in endemic areas where possibilities of co-infection exist. Further refinement in the methodology needs to be undertaken to diagnose other parasites like $T$. orientalis, $B$. bovis, $A$. centrale, etc.

\section{ACKNOWLEDGEMENT}

The author acknowledges the support and cooperation of the Director, ICAR- Research Complex for Eastern Region, Patna, for providing necessary funds and facilities for undertaking this intra-mural project. Support provided by project staff of ICAR Outreach program on Zoonotic Diseases is also duly acknowledged.

Conflict of Interest: There is no conflict to declare.

\section{REFERENCES}

Balakrishnan, N. (2017). Current scenario of tick-borne diseases in India-A review. Journal of Communicable Diseases. 49(2): 6-13.

Bilgiç, H.B., Karagenç, T., Simuunza, M., Shiels, B., Tait, A., Eren, H. and Weir, W. (2013). Development of a multiplex PCR assay for simultaneous detection of Theileria annulata, Babesia bovis and Anaplasma marginale in cattle. Experimental Parasitology. 133(2): 222-229.

El-Sayed, A. and Kamel, M. (2020). Climatic changes and their role in emergence and re-emergence of diseases. Environmental Science and Pollution Research International. 27(18): 22336-22352. doi:https://doi.org/10.1007/s11356-02008896-w.
Ganguly, A., Bisla, R.S., Singh, H., Bhanot, V., Kumar, A., Kumari, S., Maharana, B.R. and Ganguly, I. (2017). Prevalence and haematobiochemical changes of tick borne haemoparasitic diseases in crossbred cattle of Haryana, India. Indian Journal of Animal Sciences. 87(5): 552-557.

Ganzinelli, S., Benitez, D., Gantuya, S., Guswanto, A., Florin Christensen, M., Schnittger, L. and Igarashi, I. (2020). Highly sensitive nested PCR and rapid immunochromatographic detection of Babesia bovis and Babesia bigemina infection in a cattle herd with acute clinical and fatal cases in Argentina. Transboundary and Emerging Diseases. 67: 159-164. doi:10.1111/tbed.13435.

Jain, N.C. (1999). Essentials of Veterinary Hematology. Lea and Febiger, Philadelphia.

Jayalakshmi, K., Sasikala, M., Veeraselvam, M., Venkatesan, M., Yogeshpriya, S., Ramkumar, P.K., Selvaraj, P. and Vijayasarathi, M.K. (2019). Prevalence of haemoprotozoan diseases in cattle of Cauvery delta region of Tamil Nadu. Journal of Parasitic Diseases. 43(2): 308-312. doi:https://doi.org/ 10.1007/s12639-019-01094-7.

Kala, S.K., Deo, B.G. and Kumari, N. (2018). Epidemiological aspects of theileriosis in cattle in and around Patna, Bihar, India. International Journal of Current Microbiology Applied Sciences. 7: 1183-1191.

Knight, P.A., Williamson, S.W., Brown, C.G.D., Bell-Sakyi, L., Kirvar, E., Kinnaird, J., Hussain, K., Hall, R., Boulter, N. and Tait, A. (1998). Identification of a Theileria annulata antigen expressed in multiple stages of the parasite life cycle. Experimental Parasitology. 90(1): 110-121.

Kumar, B., Mondal, D. and Jithin, M. (2019). Evaluation of reactive oxidative damage on erythrocytic cells due to clinical babesiosis in lactating cows. International Journal of Livestock Research. 9(9): 55-64.

Kumar, P., Kumar, P., Roy, R.K., Kumari, R.R., Kumar, A., Sarma, K., Sharma, P. and Kumar, M. (2021). Mixed infection of tick-borne haemo-parasites in water buffalo and associated pathological responses and treatment. Indian Journal of Animal Research. doi: 10.18805/IJAR.B-4450.

Kumari, R.R., Kumar, R., Kumar, P. and Kumar, M. (2019). Emergence and variations in disease ecology of tick-borne bovine theileriosis in East India. International Journal of Livestock Research. 9(11): 12-25. doi: 10.5455/ijlr.2019092006 1236.

Kundave, V.R., Ram, H., Banerjee, P.S., Garg, R., Mahendran, K., Ravikumar, G.V.P.P.S. and Tiwari, A.K. (2018). Development of multiplex PCR assay for concurrent detection of tick borne haemoparasitic infections in bovines. Acta Parasitologica. 63(4): 759-765.

Landis, J.R. and Koch, G.G. (1977). An application of hierarchical kappa-type statistics in the assessment of majority agreement among multiple observers. Biometrics. 33(2): 363-374. doi: $10.2307 / 2529786$.

Larcombe, S., Kolte, S.W., Ponnudurai, G., Kurkure, N., Magar, S., Velusamy, R., Rani, N., Rubinibala, B., Rekha, B., Alagesan, A. and Weir, W. (2019). The impact of tickborne pathogen infection in Indian bovines is determined by host type but not the genotype of Theileria annulata. Infection, Genetics and Evolution. 75: 103972. doi:https:/ /doi.org/10.1016/j.meegid.2019.103972. 
Pain, A., Renauld, H., Berriman, M., Murphy, L., Yeats, C.A., Weir, W., Kerhornou, A., et al. (2005). Genome of the host-cell transforming parasite Theileria annulata compared with T. parva. Science. 309: 131-133.

Prabhakaran, H.S., Ghosh, K.K., Kumari, R.R., Kumar, P. and Kumar, M. (2021). Evaluation of sporozoite and macroschizont antigen (Spm2) of Theileria annulata for its diagnostic potential. Ticks and Tick-Borne Diseases. 14(4): 101691.

Roy, S., Bhandari, V., Barman, M., Kumar, P., Bhanot, V., Arora, J.S., Singh, S. and Sharma, P., (2021). Population genetic analysis of the Theileria annulata parasites identified limited diversity and multiplicity of infection in the vaccine from India. Frontiers in Microbiology. 11: 3471.
Tian Z, Tian, Z., Du, X., Du, J., Gao, S., Yu, R., Hassan, M.A., Liu, G., Luo, J. and Yin, H. (2018). Development of an indirect ELISA based on the recombinant Spm2 protein for detection of tropical theileriosis. Acta Tropica. 182: 232-236.

Trevethan, R. (2017). Sensitivity, specificity and predictive values: Foundations, pliabilities and pitfalls in research and practice. Frontiers in Public Health. 5: 307.

Turkson, P.K. and Ganyo, E.Y. (2015). Relationship between haemoglobin concentration and packed cell volume in cattle blood samples. Onderstepoort Journal of Veterinary Research. 82(1): 1-5. 